Check for updates

Cite this: Chem. Commun., 2019, 55,12491

Received 21st June 2019,

Accepted 29th August 2019

DOI: $10.1039 /$ c9cc04759j

rsc.li/chemcomm

\section{High performance photoanodic catalyst prepared from an active organic photovoltaic cell - high potential gain from visible light $\uparrow$}

\author{
Keiji Nagai, (D) *a Takayuki Kuwabara, ‡ $^{\mathrm{b}}$ Mohd Fairus Ahmad, (D) ac \\ Masahiro Nakano, (D) ${ }^{\mathrm{b}}$ Makoto Karakawa, (D) ${ }^{\mathrm{d}}$ Tetsuya Taima $^{\mathrm{d}}$ and \\ Kohshin Takahashi ${ }^{\text {b }}$
}

Photoelectrochemical oxidation of thiols was enhanced with a threshold potential of $-0.35 \mathrm{~V}$ vs. $\mathrm{Ag} / \mathrm{AgCl}$ by the use of a $\mathrm{ZnPc} /$ $\mathrm{PCBM}: \mathrm{P} 3 \mathrm{HT} / \mathrm{ZnO}$ electode, which was prepared by removing the PEDOT:PSS/Au electrode of an inverted OPV device and coating it with $\mathrm{ZnPc}$. A co-photocatalysis property of $\mathrm{ZnPc}$ was observed in the photoelectrochemistry and scanning Kelvin probe microscopy.

The organic photovoltaic (OPV) devices have potential in low-cost, large-area printing routes with high efficiency owing to the variety of organic materials. ${ }^{1}$ The active layer has a role to absorb photons and convert them to electrostatic energy in the form of separated electron and hole pairs. If the separated charge in its active layer can be utilized in chemical reactions directly without collection by electrodes, it would be a simple device for photoenergy conversion and have great merit to use the photon energy. From such a viewpoint, the research field of organic photoelectrochemical cells (OPECs) $)^{2-15}$ and organophotocatalysts ${ }^{14-19}$ has been refocused recently, while pioneer research started more than 30 years ago. ${ }^{20}$ A recent trend is metal or metal oxide coating on bulk heterojunction (BHJ) OPVs to construct OPECs and its efficiency enhancement, ${ }^{2-6}$ while the combination with rare metal is not so attractive for the choice of organic active layer. As an organic catalyst, phthalocyanine has a considerable activity and stablility. An alternative centering metal in phthalocyanine is also interesting to control its redox properties. ${ }^{13,21}$

In the conventional OPV devices, the active layer is sandwiched between a transparent electrode and an $\mathrm{Al}$ electrode as

\footnotetext{
${ }^{a}$ Laboratory for Chemistry and Life Science, Institute of Innovative Research, Tokyo Institute of Technology, R1-26, Suzukake-dai, Midori-ku, Yokohama 226-8503, Kanagawa, Japan. E-mail: nagai.k.ae@m.titech.ac.jp

${ }^{b}$ Graduate School of Natural Science and Technology, Kanazawa University, Kakuma-machi, Kanazawa, Ishikawa, 920-1192, Japan

'School of Microelectronic Engineering, Kampus Pauh, Universiti Malaysia Perlis, 02600, Arau, Perlis, Malaysia

${ }^{d}$ Nanomaterial Research Institute, Kanazawa University, Kakuma-machi, Kanazawa, Ishikawa, 920-1192, Japan

$\dagger$ Electronic supplementary information (ESI) available. See DOI: 10.1039/c9cc04759j

₹ Passed away on Dec. 5, 2017.
}

the back electrode. The so-called inverted-type OPVs have a noncorrosive Au metal as the back electrode and an ITO or a transparent front electrode. ${ }^{22-39}$ The inverted-type OPVs can be fabricated in ambient conditions and exhibit reasonable performance and stability especially with a stable n-type semiconductor, $\mathrm{TiO}_{2},{ }^{2-32} \mathrm{ZnO}^{33-38}$ or $\mathrm{ZnS},{ }^{39}$ as an electron collection layer.

For example, the ITO/amorphous $\mathrm{TiO}_{x} /[6,6]$-phenyl-C61-butyric acid methyl ester:regioregular poly(3-hexylthiophene)(PCBM:P3HT)/ poly(3,4-ethylenediox-ylenethiophene):poly(4-styrenesulfonic acid) (PEDOT:PSS)/Au inverted-type cell (ITO/TiO ${ }_{x} /$ PCBM:P3HT/PEDOT: $\mathrm{PSS} / \mathrm{Au}$ ) showed a power conversion efficiency (PCE) of $2.3 \%$ and the performance of the cells without sealing was about the same after continuous light irradiation for $100 \mathrm{~h}$ in an ambient atmosphere. ${ }^{31}$

In the present paper, the inverted-type OPV with $\mathrm{ZnO}$ was chosen as a precursor electrode to prepare a new photoanode to induce oxidation (Scheme 1). Experimental details are provided in the ESI. $\dagger$

The photovoltaic performance of the (ITO/ZnO/PCBM:P3HT/ PEDOT:PSS/Au) was confirmed as shown in Fig. S1 (ESI $\dagger$ ), and the PEDOT:PSS/Au hole collecting electrode was removed mechanically, because of weak adhesion between PCBM:P3HT and PEDOT:PSS, ${ }^{40}$

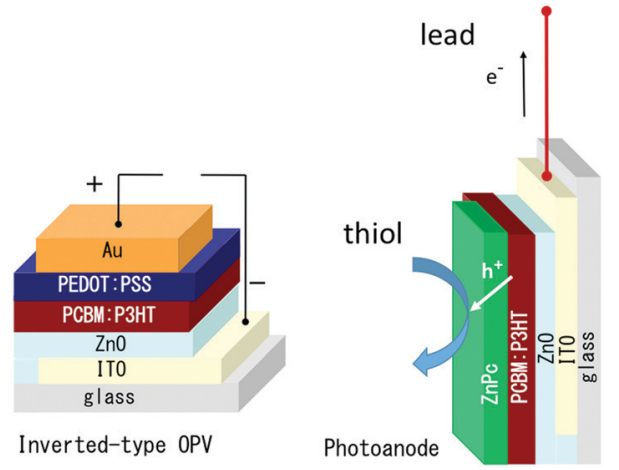

Scheme 1 The structure of the inverted-type organic photovoltaic device (left) and photoanode prepared from it by removing the hole collecting electrode and covering it with co-photocatalyst ZnPc. 
where almost complete removal of the PEDOT:PSS layer was observed. The inverted-type OPV devices have the same ordering of the layer structure as the photoanode on ITO, so the removal is a promising and repeatable technique to construct a wellcharacterized photoanode.

Fig. S2(a) (ESI $\dagger$ ) is an FE-SEM image for the cross section of the $\mathrm{BHJ}$ electrode, and indicates ordered layer structure for glass/ITO/ZnO/PCBM:P3HT. From here we denote it as the BHJ electrode. The thickness values for ITO, ZnO, and PCBM:P3HT were estimated to be $185 \mathrm{~nm}, 50 \mathrm{~nm}$, and $200 \mathrm{~nm}$, respectively. As the top view in Fig. S2(b) (ESI $\dagger$ ) shows, the sub $100 \mathrm{~nm}$ structure may be due to the roughness of the $\mathrm{BHJ}$ surface. Fig. S3 (ESI $\dagger$ ) shows visible-near-infrared absorption spectra for the $\mathrm{BHJ}$ electrode, the $\mathrm{ZnPc}$ coated $\mathrm{BHJ}$ electrode, $\mathrm{ZnPc}$ and ITO. The BHJ active layers exhibited an identical one to that of the reported ones, ${ }^{38}$ and their absorption coefficients agreed with the thickness of the film. For the ZnPc coated BHJ electrode, slight increment from that without ZnPc was observed at $>650 \mathrm{~nm}$ and was consistent with $8 \mathrm{~nm}$ coating of $\mathrm{ZnPc}$.

Fig. 1 shows voltammograms in a thiol solution for the $\mathrm{BHJ}$ electrode (a) and the ZnPc coated BHJ electrode (b). The photoanodic current (red) for the electrode with $\mathrm{ZnPc}$ (b) was much larger than that without $\mathrm{ZnPc}$ (a). For the $\mathrm{ZnPc}$ coated $\mathrm{BHJ}$ electrode with $\mathrm{ZnO}$, the threshold potential of the photoanodic current was around $-0.35 \mathrm{~V} v$ s. $\mathrm{Ag} / \mathrm{AgCl}$. For the comparison with previous data without $\mathrm{ZnO}$, a rapid scan of $20 \mathrm{mV} \mathrm{s}^{-1}$ is shown in Fig. S5b (ESI $\dagger$ ), where a similar threshold potential $(-0.38 \mathrm{~V})$ to the slow scan (Fig. 1b) was observed. On the other hand, for the $\mathrm{ZnPc}$ coated $\mathrm{BHJ}$ electrode without $\mathrm{ZnO}$, the threshold potential of the photoanodic current was around $-0.0 \mathrm{~V}$ vs. $\mathrm{Ag} / \mathrm{AgCl}$ as shown in our previous paper. ${ }^{18}$ The present larger gain than that without $\mathrm{ZnO}$ would be due to the effect of $\mathrm{ZnO}$ as a hole blocking layer. The threshold value of $-0.35 \mathrm{~V}$ vs. $\mathrm{Ag} / \mathrm{AgCl}$ was almost equal to the conduction band edge potential of $\mathrm{ZnO}$ (Fig. S6, ESI $\dagger$ ), that is, the photogenerated electrons in the $\mathrm{BHJ}$ active layer can preferentially transfer to $\mathrm{ZnO}$ when the anodic polarization of ITO was deeper than the ZnO edge. The rapid scan data showed more photoanodic current (Fig. S5b, ESI $\dagger$ ) than that for the slow scan (Fig. 1b). This means that the photoanodic performance of the photoanode is high as the diffusion limiting region of the thiol.
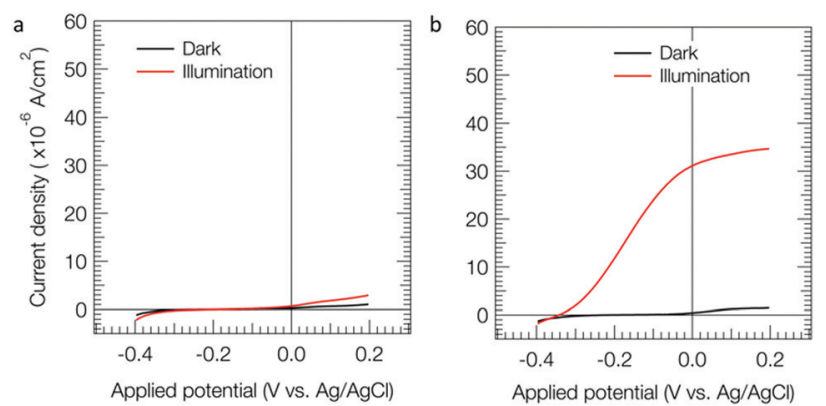

Fig. 1 Linear sweep voltammograms for the $\mathrm{BHJ}$ (a) and $\mathrm{ZnPc}$ coated $\mathrm{BHJ}(\mathrm{b})$ electrodes. Concentration of thiol, $10 \mathrm{mM}(\mathrm{pH}=11)$; light intensity, $70 \mathrm{~mW} \mathrm{~cm}^{-2}$ (Fig. S4, ESI†); scan rate, $0.5 \mathrm{mV} \mathrm{s}^{-1}$.
Note that the ZnPc electrode exhibited an anodic current in the dark as shown in Fig. S7 (ESI $\dagger$ ), that is, the ZnPc can function as a catalyst of 2-mercaptoethanol oxidation. The large anodic photocurrent may be caused by such a catalytic function of ZnPc.

Fig. 2 shows the action spectra of IPCE values (eqn (S1), $\mathrm{ESI} \dagger$ ) at a bias potential of $+0.2 \mathrm{~V} v s$. $\mathrm{Ag} / \mathrm{AgCl}$ for the steady photocurrent. The action spectrum for the $\mathrm{BHJ}$ electrode (red circle) was consistent with the visible-near infrared absorption shown in Fig. S3 (ESI $\dagger$ ). The IPCE was less than 1\%, which was negligible in comparison to that in the OPV case to be almost $100 \%$ at the maximum absorbance wavelength. ${ }^{1}$ For the $\mathrm{ZnPc}$ coated $\mathrm{BHJ}$ electrode (green square), the IPCE was $\sim 4 \%$ at $500 \mathrm{~nm}$, and much higher than that for the $\mathrm{BHJ}$ and $\mathrm{ZnPc}$ electrodes. This suggests that a significant amount of holes photoproduced in $\mathrm{BHJ}$ was transported to the catalytic $\mathrm{ZnPc}$ sites for thiol oxidation at the bias potential of $+0.2 \mathrm{~V} v s$. $\mathrm{Ag} / \mathrm{AgCl}$. Also for the near infrared region, considerable IPCE was observed for the $\mathrm{ZnPc}$ coated $\mathrm{BHJ}$ electrode as shown in the inset of Fig. 2, while the $\mathrm{ZnPc}$ and $\mathrm{BHJ}$ electrodes did not show so long a wavelength as $1100 \mathrm{~nm}$, suggesting that holes were produced on the thin ZnPc layer by an electron transfer from photoexcited ZnPc to PCBM in BHJ. ${ }^{15,41}$ After the photoanodic oxidation, the 2-mercaptoethanol would be minerarized to $\mathrm{CO}_{2}$ including an autoxidation process. ${ }^{42,43}$

The polarity of these electrodes is discussed for the rest potential change under light illumination as shown in Fig. S8 (ESI $\dagger$ ). At the time of light on, both the $\mathrm{BHJ}$ electrode and the $\mathrm{ZnPc}$ coated $\mathrm{BHJ}$ electrode exhibited a shift in the negative potential direction, while ZnPc showed a shift in the positive potential direction, which is a typical p-type semiconductor characteristic.

As shown in Fig. S7 (ESI $\dagger$ ), the electrode consisting of ZnPc alone requires the electrode potential of more than $+0.1 \mathrm{~V} v s$. $\mathrm{Ag} / \mathrm{AgCl}$ to exhibit anodic current whether the light illuminates it or not. This means that the Fermi level changes by outer bias to the level of the $\mathrm{ZnPc}$ valence band top. Because sufficient

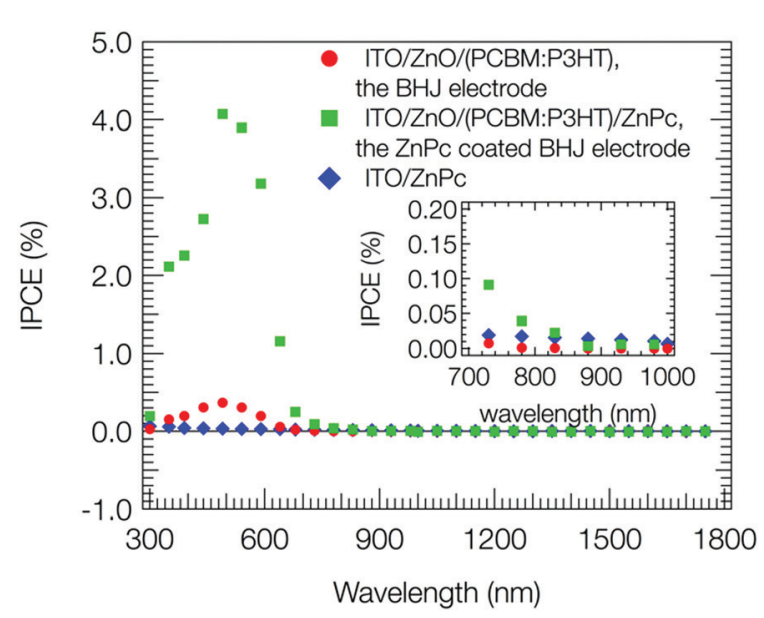

Fig. 2 Action spectra of IPCE for the ZnPc (blue), BHJ (red), and ZnPc coated $\mathrm{BHJ}$ (green) electrodes. Concentration of thiol, $10 \mathrm{mM}(\mathrm{pH}=11)$; photon flux, $1 \times 10^{16} \mathrm{~cm}^{-2} \mathrm{~s}^{-1}$; irradiation side, ITO side; bias, $+0.2 \mathrm{~V}$ vs. $\mathrm{Ag} / \mathrm{AgCl}$. The inset is enlarged view for the near infrared region. 

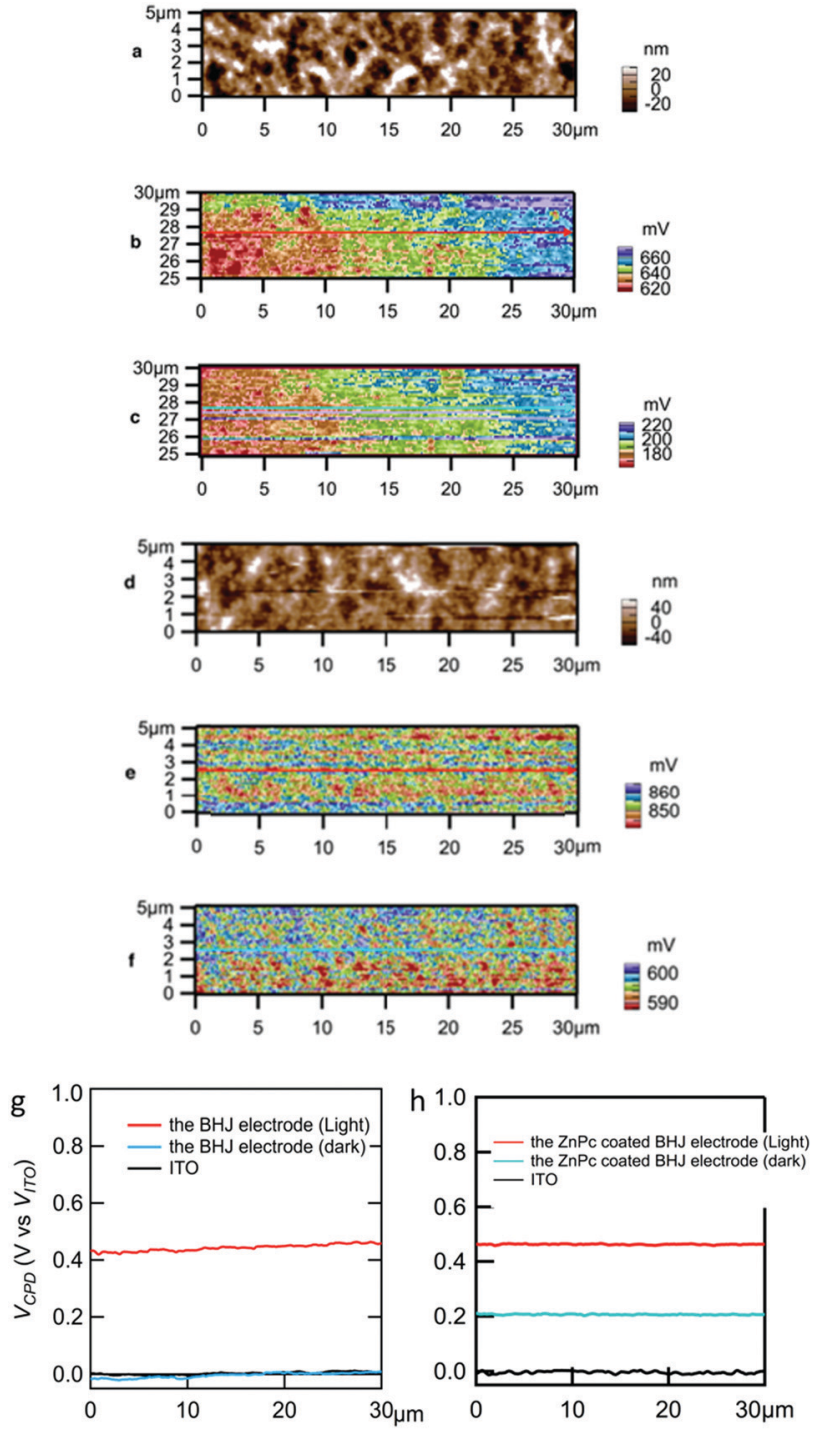

Fig. 3 (a) Topography of $30 \mu \mathrm{m} \times 5 \mu \mathrm{m}$ area for the $\mathrm{BHJ}$ electrode without $\mathrm{ZnPc}$. SKPM image for the $\mathrm{BHJ}$ electrode without $\mathrm{ZnPc}(\mathrm{b})$ in the dark and (c) under illumination. (d) Topography for the ZnPc coated BHJ electrode. SKPM image for the $\mathrm{ZnPc}$ coated $\mathrm{BHJ}$ electrode (e) in the dark and (f) under illumination. Line profile of SKPM versus the potential of ITO, (g) for the BHJ electrode without $\mathrm{ZnPc}$ and (h) for the $\mathrm{ZnPc}$ coated $\mathrm{BHJ}$ electrode. $V_{\mathrm{CPD}}$ (vs. $V_{\text {ITO }}$ ) was calculated as the difference between $V_{\text {CPD }}$ and $V_{\text {CPD }}$ of ITO.

amount of holes was produced for the $\mathrm{ZnPc}$ coated BHJ electrode under illumination, the anodic polarization of the thin ZnPc layer can be deeper than the ZnPc alone electrode, inducing the oxidation of the thiol via ZnPc. Here we adopted the scanning Kelvin probe microscope (SKPM) technique in order to verify such an anodic polarization on the $\mathrm{BHJ}$ and $\mathrm{ZnPc}$ coated $\mathrm{BHJ}$ electrodes in order to measure the surface potential. ${ }^{44}$

Fig. 3a and d show topography images for the $\mathrm{BHJ}$ and the ZnPc coated BHJ electrodes, respectively. These topographies were consistent with SEM images (Fig. S2b, ESI $\dagger$ ) in which sub $100 \mathrm{~nm}$ structure was observed. For the same areas of the topography, contact potential difference $\left(V_{\mathrm{CPD}}\right)$ was observed by the SKPM measurement as shown in Fig. 3b, c, e, and f. For comparison of these samples and conditions, the line profile values are summarized in Fig. $3 \mathrm{~g}$ and $\mathrm{h}$. The $V_{\mathrm{CPD}}$ value is the bias potential between the probe ( $\left.\varphi_{\text {probe }}\right)$ and the sample $\left(\varphi_{\text {sample }}\right)$ when the Coulomb interaction is nullified between them. ${ }^{44}$

$$
V_{\mathrm{CPD}}=\left(\varphi_{\text {probe }}-\varphi_{\text {sample }}\right) / e
$$

For the conductive sample, the $\varphi_{\text {sample }}$ value (in eV) should be equal to the work function $\left(E_{\mathrm{F}}\right.$, in eV). According to previous studies, $\varphi_{\text {probe }}$ was estimated to be in the range of 4.92-5.6 eV for Pt-coated Ir. ${ }^{45,46}$ Here, we adopt $\varphi_{\text {probe }}=5.0 \mathrm{eV}$. The SKPM measurement for ITO/ZnO acting as an electron collection electrode was done by the use of a part surface of the same $\mathrm{BHJ}$ electrode or the same ZnPc coated electrode.

The $V_{\text {CPD }}$ values of the ITO/ZnO substrates for the BHJ electrode and the $\mathrm{ZnPc}$ coated $\mathrm{BHJ}$ electrode in the dark were $0.2 \mathrm{~V}$ and $0.4 \mathrm{~V} v$ s. Pt tip, respectively. Based on eqn (1), $\varphi_{\text {sample }}$ for the ITO/ZnO is estimated to be $4.8 \mathrm{eV}$ without $\mathrm{ZnPc}$ and $4.6 \mathrm{eV}$ with $\mathrm{ZnPc}$, which are just below the conduction band edge of ZnO. Similarly, $\varphi_{\text {sample }}$ values for the BHJ and ZnPc coated BHJ electrodes in the dark were estimated to be $4.8 \mathrm{eV}$ and $4.4 \mathrm{eV}$, respectively. Fig. S6 (ESI $\dagger$ ) shows a potential diagram for the $\mathrm{ZnPc}$ coated $\mathrm{BHJ}$ electrode in the dark. When coating ZnPc, the positive shift from ITO/ZnO was observed (Fig. 3h), while it does not happen without ZnPc coating (Fig. 3g). Here we discuss the $V_{\mathrm{CPD}}$ shifts from that of ITO/ ZnO. Generally, the $V_{\mathrm{CPD}}$ value depends on substrate surface conditions, while the difference of $V_{\mathrm{CPD}}$ from the substrate one to the coating layer one was experimentally repeatable in a previous paper. ${ }^{14} \mathrm{~A}$ simple interpretation is a vacuum level shift at the $\mathrm{BHJ} / \mathrm{ZnPc}$ interface due to hole transfer from $\mathrm{BHJ}$ to ZnPc. ${ }^{46,47}$ The $\varphi_{\text {sample }}$ in the dark ( $\left.\varphi_{\text {dark }}\right)$ should be constant as shown in Fig. S6 (ESI $\dagger$ ) (blue line). This means that an interfacial dipole layer ${ }^{48}$ consisting of negatively charged $\mathrm{BHJ}$ and positively charged ZnPc, which are shown by symbols - and + in Fig. S6 (ESI $\dagger$ ), was formed at the BHJ/ZnPc interface.

The actual electrochemical response was enhanced under light illumination especially with ZnPc coating (Fig. 2). Under illumination, the $V_{\mathrm{CPD}}$ values were more positive than those in the dark for both ZnPc coating and without coating. From eqn (1), the

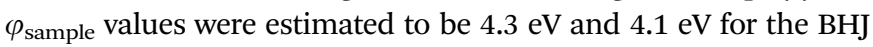
and $\mathrm{ZnPc}$ coated BHJ electrodes, respectively. Both of the $\varphi_{\text {sample }}$ values were shallower than the conduction band edge of $\mathrm{ZnO}$, which was consistent with the photoanodic current generation under illumination. The positive shift of $V_{\mathrm{CPD}}$ from the dark condition means hole accumulation at the surface which encountered the (negatively charged) tip without bias. During SKPM measurement, in order to compensate the charge, the bias was applied between sample and tip as $V_{\mathrm{CPD}}$.

As for the ZnPc coated BHJ electrode, the $\varphi_{\text {sample values in }}$ the dark were in the middle between those of the ITO/ZnO substrate and under illumination. The reason of the shift in the dark was described above as a vacuum level shift. Furthermore, here a possible factor of charge accumulation at the interface between $\mathrm{BHJ}$ and $\mathrm{ZnPc}$ would be very long relaxation time after the charge separation process. In various OPV devices, a long relaxation time was reported after light illumination; for 
example, according to an ESR observation, amorphous $\mathrm{TiO}_{x}$ can trap electrons and counter P3HT cation radicals have such a long lifetime. ${ }^{32}$ The reason is not inconsistent with the above discussion for the vacuum level shift.

To summarize, $\mathrm{BHJ}$ films with $\mathrm{ZnO}$ as a hole blocking layer were utilized for OPECs after removing the PEDOT:PSS/Au electrode of OPV devices with inverted structures. The $\mathrm{ZnO}$ layer was effective in comparison with its absent system for the electron injection from the active $\mathrm{BHJ}$ layer to the ITO substrate electrode, resulting in a threshold potential shift to $-0.35 \mathrm{~V} v s$. $\mathrm{Ag} / \mathrm{AgCl}$ for the $\mathrm{ZnPc}$ coated $\mathrm{BHJ}$ electrode. The effect of $\mathrm{ZnPc}$ was clearly observed in the SKPM measurement as an accumulation of the photogenerated holes to ZnPc. Remarkable enhancement of the photoanodic current was observed only by coating of $\mathrm{ZnPc}$, although the potential gain by the $\mathrm{BHJ}$ active layer was the same as that without $\mathrm{ZnPc}$ as seen in the rest potential change. Since an anodic current by the ZnPc electrode in the dark condition means it functions as a catalyst for thiol oxidation, the remarkable enhancement means that the ZnPc coated on BHJ also effectively functioned as a co-photocatalyst.

We thank the Dynamic Alliance for Open Innovation Bridging Human, Environmental and Materials from MEXT. We also thank the Suzukakedai Materials Analysis Division, Technical Department, Tokyo Institute of Technology, for assistance with SEM analysis and SKPM measurements.

\section{Conflicts of interest}

There are no conflicts to declare.

\section{References}

1 O. Inganäs, Adv. Mater., 2018, 30, 1800388.

2 J. T. Kirner and R. G. Finke, J. Mater. Chem. A, 2017, 5, 19560.

3 F. Fumagalli, S. Bellani, M. Schreier, S. Leonardi, H. C. Rojas, A. Ghadirzadeh, G. Tullii, A. Savoini, G. Marra, L. Meda, M. Grätzel, G. Lanzani, M. T. Mayer, M. R. Antognazza and F. Di Fonzo, J. Mater. Chem. A, 2016, 4, 2178.

4 L. Yao, A. Rahmanudin, N. Guijarro and K. Sivula, Adv. Energy Mater., 2018, 8, 1802585.

5 L. Steier and S. Holliday, J. Mater. Chem. A, 2018, 6, 21809.

6 C. D. Windle, S. Chandrasekaran, H. Kumagai, G. Sahara, K. Nagai, T. Abe, M. Chavarot-Kerlidou, O. Ishitani and V. Artero, Molecular Design of Photocathode Materials for Hydrogen Evolution and Carbon Dioxide Reduction, in Molecular Technology: Energy Innovation, ed. H. Yamamoto and T. Kato, Wiley, 2018, ch. 10, pp. 251-286.

7 T. Abe, Y. Tanno, N. Taira and K. Nagai, RSC Adv., 2015, 5, 46325.

8 T. Abe, K. Nagai, M. Kaneko, T. Okubo, K. Sekimoto, A. Tajiri and T. Norimatsu, ChemPhysChem, 2004, 5, 716.

9 T. Abe, K. Nagai, M. Kaneko, S. Kabutomori, A. Tajiri and T. Norimatsu, Angew. Chem., Int. Ed., 2006, 45, 2778.

10 L. Wang, D. Yan, D. W. Shaffer, X. Ye, B. H. Layne, J. J. Concepcion, M. Liu and C.-Y. Nam, Chem. Mater., 2018, 30, 324.

11 F. C. A. Guerrero, M. Haro, S. Bellani, M. R. Antognazza, L. Meda, S. Gimenez and J. Bisquert, Energy Environ. Sci., 2014, 7, 3666.

12 M. F. Ahmad, T. Abe, C. S. A. Musgrave and K. Nagai, Electrochemistry, 2018, 86, 235.

13 T. Abe, S. Miyakushi, K. Nagai and T. Norimatsu, Phys. Chem. Chem. Phys., 2008, 10, 1562.
14 M. F. Ahmad, M. Suzuki, T. Abe and K. Nagai, NPG Asia Mater., 2018, 10, 630 .

15 T. Abe, M. Ichikawa, T. Hikage, S. Kakuta and K. Nagai, Chem. Phys. Lett., 2012, 549, 77.

16 K. Nagai, Y. Yasuda, T. Iyoda and T. Abe, ACS Sustainable Chem. Eng., 2013, 1, 1033.

17 K. Nagai, T. Abe, Y. Kaneyasu, Y. Yasuda, I. Kimishima, T. Iyoda and H. Imaya, ChemSusChem, 2011, 4, 727.

18 R. S. Sprick, B. Bonillo, M. Sachs, R. Clowes, J. R. Durrant, D. J. Adamsa and A. I. Cooper, Chem. Commun., 2016, 52, 10008.

19 M. Sachs, R. S. Sprick, D. Pearce, S. A. J. Hillman, A. Monti, A. A. Y. Guilbert, N. J. Brownbill, S. Dimitrov, X. Shi, F. Blanc, M. A. Zwijnenburg, J. Nelson, J. R. Durrant and A. I. Cooper, Nat. Commun., 2018, 9, 4968.

20 S. Yanagida, A. Kabumoto, K. Mizumoto, C.j. Pac and K. Yoshino, J. Chem. Soc., Chem. Commun., 1985, 475.

21 D. Schlettwein, M. Kaneko, A. Yamada, D. Wöhrle and N. I. Jaeger, J. Phys. Chem., 1991, 95, 1748.

22 Y. Sahin, S. Alem, R. de Bettignies and J.-M. Nunzi, Thin Solid Films, 2005, 476, 340.

23 T. Kuwabara, T. Minami, T. Kusumi, T. Yamaguchi, T. Taima and K. Takahashi, Electrochemistry, 2017, 85, 262.

24 R. Steim, S. A. Choulis, P. Schilinsky and C. J. Brabec, Appl. Phys. Lett., 2008, 92, 093303.

25 H. Schmidt, H. Flugge, T. Winkler, T. Bulow, T. Riedl and W. Kowalsky, Appl. Phys. Lett., 2009, 94, 243302.

26 S. K. Hau, H.-L. Yip, H. Ma and A. K.-Y. Jen, Appl. Phys. Lett., 2008, 93, 233304.

27 A. Hayakawa, O. Yoshikawa, T. Fujieda, K. Uehara and S. Yoshikawa, Appl. Phys. Lett., 2007, 90, 163517.

28 J. Y. Kim, K. Lee, N. E. Coates, D. Moses, T.-Q. Nguyen, M. Dante and A. J. Heeger, Science, 2007, 317, 222.

29 G. K. Mor, K. Shankar, M. Paulose, O. K. Varghese and C. A. Grimes, Appl. Phys. Lett., 2007, 91, 152111.

30 T. Kuwabara, T. Nakayama, K. Uozumi, T. Yamaguchi and K. Takahashi, Sol. Energy Mater. Sol. Cells, 2008, 92, 1476.

31 T. Kuwabara, H. Sugiyama, M. Kuzuba, T. Yamaguchi and K. Takahashi, Org. Electron., 2010, 11, 1136.

32 T. Kuwabara, K. Yano, K. Takahashi, D. Son and K. Marumoto, J. Phys. Chem. C, 2015, 119, 5274.

33 E. Itoh, S. Sakai and K. Fukuda, Jpn. J. Appl. Phys., 2018, 57, 03EJ07.

34 K. Takanezawa, K. Tajima and K. Hashimoto, Appl. Phys. Lett., 2008, 93, 063308.

35 T. Fukuda and Y. Uratani, Electrochemistry, 2017, 85, 249.

36 D. Li, W.-j. Qin, S.-c. Zhang, D.-y. Liu, Z.-y. Yu, J. Mao, L.-f. Wu, L.-y. Yang and S.-g. Yin, RSC Adv., 2017, 7, 6040.

37 B. Wu, Z.-h. Wu, Q.-y. Yang, F.-r. Zhu, T.-W. Ng, C.-S. Lee, S.-H. Cheung and S.-K. So, ACS Appl. Mater. Interfaces, 2016, 8, 14717.

38 T. Kuwabara, Y. Omura, K. Takahashi, V. Vohra and H. Murata, J. Phys. Chem. C, 2014, 118, 4050.

39 T. Kuwabara, M. Nakamoto, Y. Kawahara, T. Yamaguchi and K. Takahashi, J. Appl. Phys., 2009, 105, 124513.

40 M. Karakawa, N. Ohmae, T. Nagai, T. Kusumi, T. Kuwabara, T. Taima, T. Yamaguchi and K. Takahashi, Org. Electron., 2019, 66, 76.

41 J. Bian, J. Feng, Z. Zhang, Z. Li, Y. Zhang, Y. Liu, S. Ali, Y. Qu, L. Bai, J. Xie, D. Tang, X. Li, F. Bai, J. Tang and L. Jing, Angew. Chem., Int. Ed., 2019, 58, 10873.

42 S. Zhang, P. Arunachalam, T. Abe, T. Iyoda and K. Nagai, J. Photochem. Photobiol., A, 2012, 244, 18.

43 P. Arunachalam, S. Zhang, T. Abe, M. Komura, T. Iyoda and K. Nagai, Appl. Catal., B, 2016, 193, 240.

44 Kelvin Probe Force Microscopy, ed. S. Sadewasser and T. Glatzel, Springer Series in Surface Science, 2011, vol. 48, p. 12.

45 D. Yamashita and A. Ishizaki, Appl. Surf. Sci., 2016, 363, 240.

46 F. Yan, G. Chen, L. Lu and J. E. Spanier, ACS Nano, 2012, 6, 2353.

47 D. J. Ellison, J. Y. Kim, D. M. Stevens and C. D. Frisbie, J. Am. Chem. Soc., 2011, 133, 13802.

48 H. Ishii, K. Sugiyama, E. Ito and K. Seki, Adv. Mater., 1999, 11, 605. 